\section{Reproductive and Sexual Coer- cion: The Role of Alcohol, Social and Demographic Conditions}

Keywords: Intimate partner violence; Reproductive coercion Contraception; Alcoholism; Migrations

\begin{abstract}
Reproductive coercion is defined as partner behaviors that interfere with effective use of contraception. The contraception sabotage includes hiding, withholding and destroying of contraceptives in an attempt to induce pregnancy despite a female partner's wishes to prevent the pregnancy. In the literature, contraception sabotage is usually discussed as an intentional act. It has been suggested to extend the definition by adding the reproductive coercion by negligence, in particular, the sabotage of agreed or presupposed method of contraception, which sometimes happens under the impact of alcohol. Five case histories are presented here. The social background and cause-effect relationships between certain behavioral stereotypes, alcohol consumption and heavy binge drinking are analyzed. The use of condoms is dependent on personal characteristics and the level of social development; however, alcohol consumption at sexual encounters and heavy binge drinking are potential risk factors for the non-use of condoms and other irresponsible behaviors. The sexual and reproductive coercion is sometimes used for the purpose of migration to cement a relationship or to spread a certain genotype. Vasectomy may be a viable solution for some individuals incapable to control their behavior and consistently use condoms, although it does not eliminate the necessity of condoms to prevent sexually transmitted infections.
\end{abstract}

\section{Introduction}

Reproductive coercion (RC) interferes with a woman's decisionmaking regarding reproductive health; it may consist of contraception sabotage and/or pressure to either carry a pregnancy to term or to have an abortion [1]. The RC definitions include male partners' attempts to promote pregnancy through verbal pressure and threats [2]. The contraception sabotage includes hiding, withholding or destroying contraceptives, deliberate tearing or removing of condoms or failing to withdraw in an attempt to induce pregnancy despite a female partner's wishes to prevent the pregnancy [3]. Reproductive coercion is not always defined as such by the victim; in particular, intimate partner violence (IPV) may prevent a woman from naming certain behaviors as coercion [1]. In the literature, RC is usually discussed as intentional act. It has been suggested to extend the definition by adding the "RC by negligence", in particular, the sabotage of agreed or presupposed method of contraception, which sometimes happens under the impact of alcohol [4]. Admittedly, it may be difficult to distinguish between the negligence, subconscious and conscious intentions.

The abortion rate in the former Soviet Union (SU) has been the world highest [5], caused not only by the insufficient availability of modern contraception but also by an irresponsible behavior sometimes in conditions of excessive alcohol consumption. According
Journal of

\section{Addiction \& Prevention}

to a systematic review and meta-analysis, consistent condom use was less prevalent among hazardous vs. regular drinkers in Russia [6]. Fortunately, both the abortion rate and alcohol consumption in Russia tend to decrease $[7,8]$. It seems that at different times there have been official or unofficial directives aimed at the birth rate elevation initially in conditions of the gender imbalance after the World War II. This resulted in a limited availability of contraceptives, unavailability of voluntary sterilization, and prohibition of abortions till 1955 along with the propagation of consumerist attitude to women: corresponding talks and behaviors have been quite usual. The official atheism obviously contributed to irresponsible and immoral behaviors [9]. In the meantime, the gender imbalance has reverted and global overpopulation has come to the fore; but fertility is stimulated now as before. For example, some popular TV series such as the "Sled" (Trace) and "Slepaia" (The Blind) regularly present unexpected and unintended pregnancies both in and out of wedlock as something natural and unavoidable while contraception is mentioned rarely. Remarkably, in the Episode 306 of the latter series (shown by TV3 on 10 November 2020) a gynecologist at a husband's request surreptitiously replaced contraceptive pills by vitamins. This was presented by the filmmakers as a good deed as the husband wanted children but the wife did not. The risks associated with oral contraceptives are invented or exaggerated by mass media and some literature. Apparently, the propaganda follows policies aimed at the birth rate elevation. Among the background factors are the machismo ideation, disrespect for some laws and regulations, abundant violence and death on TV indirectly trivializing the child and elder abuse, sexual and reproductive coercion. In the author's opinion, authorities should handle the neglectful and intentional contraception sabotage as offenses with infliction of bodily harm if an abortion or unintended pregnancy followed. Of note, a majority of studies on these topics have been performed in more developed countries, while dimensions of the problem in less open societies are difficult to assess. In particular, the rape myth, an ideology excusing sexual assault and/or blaming victims for their own sexual victimization, is widespread in some sociocultural settings $[10,11]$. The relatively high level of alcohol consumption is believed to be a factor contributing to the irresponsible sexual behavior and IPV. Five 
case histories are presented here followed by an overview of literature. Certain cases were reported to the authorities after a delay as the denunciation of illegal and immoral acts was unusual in the former SU especially of those committed by individuals from the privileged milieu (exemplified by Case 1).

\section{Case Series}

(1) A son of a higher officer awarded himself a next rank every time he was infected with gonorrhea. In this way he became a "generalissimo" illustrating irresponsibility - the patient was proud of his "career". He was one of the informal leaders of a company that, apart from selling to foreigners of icons and silver coins (fartsovka: https://en.wikipedia.org/wiki/Fartsovka), involved adolescents in the binge drinking and teenage girls into sexual contacts e.g. with participants of international exhibitions in Moscow and foreign truck drivers. Individuals infected with $N$. gonorrheae and other sexually transmitted infections (STI) avoided the dermato-venereological prevention and treatment centers (so-called dispensaries), where the treatment was lengthy and unpleasant, and treated themselves with antibiotics [12]. Intramuscular injections of Hexestrol (Synoestrol) oil solution were used to induce abortions - a well-known method of self-induced abortions in the former SU. The case was reported to the authorities; the informer made no secret of that, later he underwent assault and battery. It is known that some sons of higher officers and functionaries were prone to promiscuity regarded as manly behavior. This case demonstrates that the society and its institutions factually permitted the spread of STI. Being informed of the lengthy and unpleasant treatments, high-risk groups avoided the governmental medical institutions, practiced self-treatment and/ or continued spreading STI. Some female patients, especially those seen as socially unprotected or "immoral", recollected harsh and painful gynecological examinations, abortions etc., whereas personal judgment and ideation of punishment have apparently played a role [12].

(2) A case of child abuse followed by alcohol overconsumption by the victim was reported previously [13]. The ethnic factor obviously played a role as the abuser was of Jewish descent while the victim was ethnic Russian. The history had a prequel. A 33-years-old single mother with a 5-year-old son was visiting at her relatives in one of the Baltic republics. The head of the inviting family was an officer; there had been violence in his family. The officer had a 20 -years-old son, who (together with his friend) sexually assaulted the visiting mother's cousin. Two years later the offender married the victim pregnant at that time. Under conditions of the Soviet registration system, aimed to counteract a mass migration to the Capital, factual and fictive marriages were often used to obtain a residence permit (propiska) in Moscow. In the former SU, the registration and accommodation have been strong motives especially for the cities attracting immigrants. It is known that, in some cultural settings with a rape myth acceptance, sexual violence was a method of acquiring wives $[14,15]$. The fact that some victims married their rapists was erroneously seen as indication that women enjoy it; in fact, existing accounts demonstrate various degrees of trauma [15]. As mentioned above, high social positions held by offenders or their relatives generally impeded reporting. (3) The victim of child abuse was prone to alcohol consumption and binge drinking during his adolescence and early adulthood. Cause- effect mechanisms have been discussed previously [13]. At the age of 22 years he started relationship with a 7 years older woman coming from another Soviet republic. Having no accommodation in Moscow, she had a motive to maintain the relationship. This motive is known also in other countries, where individuals lacking affordable housing feel coerced to maintain unsafe relationships [16]. The female partner participated in the binge drinking taking smaller doses. The heavy binge drinking was occasionally accompanied by neglect of the agreed withdrawal method of contraception. During four years' cohabitation there was "only" one abortion induced by intramuscular injections of Hexestrol (Synoestrol). However, the neglectful stereotype has been repeated also with other partners, which resulted in two more abortions at least. This behavior was explicable within the scope of frontal lobe dysfunction (discussed below) and Klüver-Bucy syndrome after a childhood head trauma and prolonged alcohol intake with heavy binges: irresponsible behaviors, lack of concern about consequences and morals, loss of normal fear and anger responses, partial visual agnosia and amnesia [17]. Moreover, IPV sometimes occurred in connection with drinking binges. Apparently, it was an example of the intergenerational transmission [18] i.e. continuation of IPV practiced by the stepfather and mother, who both had been victims of physical abuse in their childhood.

(4) In the 7th class of a school (13-14 years old children) appeared two brothers from one of the Transcaucasian republics of the former $\mathrm{SU}$, both early-ripening. It came out later that they had seduced or raped several girls, which resulted in one abortion at least. One of the girls recollected that it happened so quickly that she noticed it when it was too late: the boy was adroit; apparently, he had been instructed within his family. Sexual experiences with relatives are not unusual in certain environments [19]. In particular, mother-son and sisterbrother relationships may result in teenagers feeling themselves as men and acting as such when they deem it safe. It was reported that $49 \%$ of "child perpetrators" had been sexually abused prior to their own abusive behaviors [20].

(5) This case is a composite from different individuals; it summarizes the topic of date rape, which has rarely been recognized and prosecuted as such in the former SU, if not arranged as a trap. He invites her or vice versa, then she says "no"; there follows a more or less intensive resistance. Definitions of the non-consent and coercion are not always straightforward in such cases. Studies indicate that sexually aggressive acts often do not involve the condom use, while the offender's alcohol consumption and condom non-use tend to correlate [21]. The condom use is inconvenient in the settings of sexual violence but the withdrawal method of contraception can be applied. Alcohol may contribute to a misperception of intentions [22]. It has been assumed that alcohol impairs a woman's ability to recognize the sexual assault risk and to resist advances [23]. Although intoxication is not a prerequisite of the sexual violence, their cooccurrence suggests that alcohol sometimes plays a causative role [24]. Of note, a case is classified as rape if a victim is incapacitated by drugs or alcohol being unable to give valid consent. One rationale for the date rape is that women going into dates know that men expect sex; therefore, if a woman did not intend it, she should not agree to a date. By analogy with the informed consent in medicine, there can be no situations where a person gives up her or his right to say "no" to any kind of sexual activity [25]. It is important to mention that among 
risk factors of the date rape and contraception sabotage is the hostility toward women $[11,26]$, either to all of them or to a certain ethnic or another type. A direct association between misogynistic attitudes and coercion aimed at unprotected sex has been noticed [21]. This may be a conscious or subconscious "retaliation" for some true or imagined insults in the past while sexual encounters provide opportunities for revenge. Finally, the rape in marriage and partnership should be mentioned; which has often been regarded as norm [15]. As discussed above, the rape culture is an ideology supporting or excusing sexual assault [11]. Hopefully, today the matters are improving together with a decline in the alcohol consumption and heavy binge drinking in the former SU $[7,8]$.

\section{Discussion}

An association between the alcohol consumption and negligent behavior is explainable within the framework of alcohol myopia theory. The cognitive capacity is impaired under the impact of alcohol, so that intoxicated individuals concentrate their attention on the cues that are momentarily significant for them. The immediate sexual engagement involves the limited cognitive resources, while more remote cues, such as the risk of STI or unintended pregnancy, are ignored $[27,28]$. Remarkably, inebriated persons may concentrate their attention on risks and display more prudent behavior if salient features of the encounter emphasize the risks [29]. For example, alcohol tended to enhance the condom use in women from certain ethnic backgrounds presumably through diminishing anxiety about proposing condoms [30]. The data that the condom use was relatively frequent among heavy episodic drinkers [31] agree with our observations: individuals with alcohol dependence and increased tolerance may preserve a high level of risk perception and behavioral skills in the state of intoxication. However, personality changes slowly progressing after a prolonged alcohol overconsumption and heavy binge drinking (discussed below) might sooner or later interfere with the risk perception and social skills. In addition, the heavy binge drinking is associated with severe hangovers, which are sometimes accompanied by depression that in turn is associated with unprotected sex [32].

Apart from immediate effects of the alcohol intake, consequences of a prolonged alcohol overconsumption and heavy binge drinking should be taken into account. The term "alcoholic dementia", used in the former SU, does not exactly correspond to the term "alcohol-related dementia" used in other countries because the latter comprises consequences of head trauma, undernourishment, protein and vitamin (especially thiamine) deficiency, toxicity by substances other than ethanol in poor-quality beverages [33] that may contribute to the damage of neural structures and advancement of personality changes. Manifestations of alcohol-related dementia and frontal syndrome partly overlap, sharing the personal and social neglect, derangements of the cognitive capacity with impaired perception of risks, disinhibition, lack of concern about consequences and morals [34-41]. Aggressive behavior is known to occur in alcoholrelated dementia, which is beyond the scope of this review. Of note, aggression in alcoholics is sometimes intentionally provoked by female partners and/or other persons. The alcohol administration research demonstrated that people behave more aggressively when drinking; however, these effects are strongest in individuals predisposed to aggression. Overall, surveys indicated that personality characteristics, attitudes, and past experiences of sexual perpetrators who drink during the assault are similar to those who don't. Many perpetrators commit multiple sexual assaults, some of them when drinking and some when sober. Apparently, alcohol interacts with the personality and some aspects of the situation, enhancing the risk of perpetration among men already predisposed to aggression [24]. Domestic and sexual violence is often combined with the alcohol abuse, while the use of condoms in the context of violence is less probable [42]. There is also an opposing opinion that violence leads to an increased condom use, explained by a loss of trust and intimacy [43]. This may be true for milder cases, when the victim is not intimidated by her violent partner. In this connection, it is important to distinguish between the relationship dysfunction and violent entrapment or "battered woman syndrome" including the learned helplessness [44,45]. RC is regarded to be a form of IPV; it can lead to unintended pregnancy, abortion, poor pregnancy outcomes, STI, psychological trauma and depression [2,3,46,47]. Among potential contributing factors are disrespect for laws and regulations, impunity of some offenses and offenders, habitual display of death and violence on TV indirectly trivializing less spectacular phenomena such as the IPV, sexual and reproductive coercion.

Furthermore, relationships between the safer sex decision making and alcohol intake depend on the level of sociocultural development. Multiple studies performed in more developed countries did not unequivocally confirm the association between alcohol consumption and non-use of condoms [31,48-54]. According to some research, only very high levels of alcohol intake reduce the probability of condom use [30]. On the contrary, all known studies performed in less developed or recently industrialized parts of the world confirmed the association of the alcohol intake with the non-use of condoms and other risky sexual behaviors [55-62]. It can be reasonably assumed that the social progress correlates with improvements of morality, so that distracting factors such as alcohol lose their significance. However, international migrations confound this scheme while the alcoholrelated negligence sometimes gives way to migration-related and geopolitical motives [63]. Fictive and temporary marriages have been used for obtaining the registration and accommodation in Moscow as well as in other cities attracting migrants. As exemplified by the Cases 2 and 4, the sexual and reproductive coercion are sometimes used intentionally for the purpose of migration, to cement a relationship and/or to spread a certain genotype. Cases are known when heritable disease in a perpetrator was concealed from the partner and then acquired by the offspring. Various methods are applied: persuasion and seduction, alcohol and drugs, sexual and reproductive coercion, intimidation and IPV. Considering the forthcoming globalization, women should be aware of these strategies.

\section{Conclusion}

Interventions for gender-based violence should include the screening for reproductive coercion and confidential counseling [64]. Vasectomy is a viable solution for some males incapable and/ or unwilling to control their behavior and consistently use condoms, although it does not eliminate the necessity of condoms to prevent STI. Admittedly, surgical sterilization can be seen as a violation of the bodily integrity. The same, however, can be said about sexual and 
reproductive coercion. It should be stressed that vasectomy is a safe and efficient method of permanent contraception; it was reported to be 30 times less likely to fail and 20 times less likely to have postoperative complications than tubal ligation in women. Complications of vasectomy are rare and minor in nature $[65,66]$. Vasectomy is mentioned here because it is obviously preferable to the unintended pregnancy and abortion. As per the tubal ligation, its combination with cesarean section (CS), i.e. cesarean tubal ligation, should be generally considered for women not planning further pregnancies. Certainly, the latest delivery is not necessarily the last one, because circumstances may change after the delivery. The age and attitude of the male partner should be taken into account. However, CS on maternal request must be available also in the absence of contraindications for attempting vaginal delivery. This pertains also to Russia, where CS is usually not performed on a maternal request [67]. Certain authors reported that they had performed CS on maternal request whereas countrywide CS is performed more frequently when the procedure is paid on by patients [68]. Other experts insist that SC must be done only in accordance with indications. In the author's opinion, the worldwide increase in the percentage of deliveries performed by CS is a positive development. A more frequent use of the cesarean tubal ligation would be especially favorable for overpopulated regions with a gender imbalance; details and references are in [69].

\section{References}

1. Grace KT (2016) Caring for women experiencing reproductive coercion. J Midwifery Womens Health 61: 112-115.

2. McGirr SA, Bomsta HD, Vandegrift C, Gregory K, Hamilton BA, et al. (2020) An examination of domestic violence advocates' responses to reproductive coercion. J Interpers Violence 35: 2082-2106.

3. Silverman JG, Raj A (2014) Intimate partner violence and reproductive coercion: global barriers to women's reproductive control. PLoS Med 11: e1001723.

4. Jargin SV (2017) Condom use, alcohol, and reliability of survey data. Int $J$ High Risk Behav Addict 6: e31577.

5. United Nations, Department of Economic and Social Affairs Population Division (2013) World Abortion Policies. United Nations, New York.

6. Lan CW, Scott-Sheldon LA, Carey KB, Johnson BT, Carey MP (2017) Prevalence of alcohol use, sexual risk behavior, and HIV among Russians in high-risk settings: A systematic review and meta-analysis. Int J Behav Med 24: $180-190$

7. Neufeld M, Ferreira-Borges C, Gil A, Manthey J, Rehm J (2020) Alcohol policy has saved lives in the Russian Federation. Int J Drug Policy 80: 102636.

8. Perlman FJ (2010) Drinking in transition: trends in alcohol consumption in Russia 1994-2004. BMC Public Health 10: 691.

9. Adamczyk A (2012) Extracurricular activities and teens' alcohol use: The role of religious and secular sponsorship. Soc Sci Res 41: 412-424.

10. Cooke EM, Lewis RH, Hayes BE, Bouffard LA, Boisvert DL, et al. (2020) Examining the relationship between victimization, psychopathy, and the acceptance of rape myths. J Interpers Violence 18: 886260520966669.

11. Johnson NL, Johnson DM (2021) An empirical exploration into the measurement of rape culture. J Interpers Violence 36: 70-95.

12. Jargin SV (2012) About the treatment of gonorrhea in the former Soviet Union. Dermatol Pract Concept. 2: 12.

13. Jargin SV (2017) Child abuse, autism and excessive alcohol consumption. $J$ Addiction Prevention 5: 4

14. Renzetti CM, Edleson JL, Bergen RK (2012) Companion reader on violence against women. Sage, Los Angeles.
15. Russell DEH (1990) Rape in marriage. McMillan, New York.

16. Rosenbaum JE, Zenilman J, Rose E, Wingood G, DiClemente R (2016) Predicting unprotected sex and unplanned pregnancy among urban AfricanAmerican adolescent girls using the theory of gender and power. J Urban Health 93: 493-510

17. Jargin SV (2020) Klüver-Bucy syndrome after a head trauma in conditions of child abuse and neglect. Psychiatr Danub 32: 434-435.

18. Hayes BE, Randa R (2021) Parts Unknown: Risk Factors of Intimate Partner Violence in Azerbaijan, Kyrgyzstan, Tajikistan, and Moldova. J Interpers Violence 36: NP3346-NP3368.

19. Solorzano E, Arroyo G, Santizo R, Contreras C, Gularte M (1992) Sexually transmitted diseases in Guatemala City street children. Rev Col Med Cir Guatem 2 Suppl: 48-51.

20. Johnson TC (1988) Child perpetrators - children who molest other children: preliminary findings. Child Abuse Negl 12: 219-229.

21. Davis KC, Kiekel PA, Schraufnagel TJ, Norris J, George WH (2012) Men's alcohol intoxication and condom use during sexual assault perpetration. J Interpers Violence 27: 2790-2806.

22. Farris C, Treat TA, Viken RJ, McFall RM (2008) Sexual coercion and the misperception of sexual intent. Clin Psychol Rev 28: 48-66.

23. Testa M, Livingston JA (2009) Alcohol consumption and women's vulnerability to sexual victimization: can reducing women's drinking prevent rape? Subst Use Misuse 44: 1349-1376.

24. Abbey A (2011) Alcohol's role in sexual violence perpetration: theoretical explanations, existing evidence and future directions. Drug Alcohol Rev 30: 481-489.

25. Frese B, Moya M, Megías JL (2004) Social perception of rape: how rape myth acceptance modulates the influence of situational factors. $J$ Interpers Violence 19: 143-161

26. Wegner R, Davis KC, Stappenbeck CA, Kajumulo KF, Norris J, (2017) The effects of men's hostility toward women, acute alcohol intoxication, and women's condom request style on men's condom use resistance tactics. Psychol Violence 7: 593-601.

27. Scott-Sheldon LA, Carey KB, Cunningham K, Johnson BT, Carey MP, et al. (2016) Alcohol use predicts sexual decision-making: A systematic review and meta-analysis of the experimental literature. AIDS Behav 20(Suppl 1) : 19-39.

28. Weinhardt LS, Carey MP (2000) Does alcohol lead to sexual risk behavior? Findings from event-level research. Annu Rev Sex Res 11: 125-157.

29. MacDonald TK, Fong GT, Zanna MP, Martineau AM (2000) Alcohol myopia and condom use: can alcohol intoxication be associated with more prudent behavior? J Pers Soc Psychol 78: 605-619.

30. Walsh JL, Fielder RL, Carey KB, Carey MP (2014) Do alcohol and marijuana use decrease the probability of condom use for college women? J Sex Res 51: 145-158.

31. Scott-Sheldon LA, Carey MP, Carey KB, Cain D, Harel O, et al. (2012) Patterns of alcohol use and sexual behaviors among current drinkers in Cape Town, South Africa. Addict Behav 37: 492-497.

32. Islam N, Laugen C (2015) Gender differences in depression and condom use among sexually active Canadians. J Affect Disord 174: 511-515.

33. Jargin SV (2017) Popular alcoholic beverages in Russia with special reference to quality and toxicity. J Addiction Prevention 5: 6 .

34. Ropper AH (1979) A rational approach to dementia. CMAJ 121: 1175-1190.

35. Mewton L, Lees B, Rao RT (2020) Lifetime perspective on alcohol and brain health. BMJ 371: m4691.

36. Gupta S, Warner J (2008) Alcohol-related dementia: a 21st-century silent epidemic? Br J Psychiatry 193: 351-353.

37. Brun A, Andersson J (2001) Frontal dysfunction and frontal cortical synapse loss in alcoholism - the main cause of alcohol dementia? Dement Geriatr Cogn Disord 12: 289-294. 
38. Grodin EN, Lin H, Durkee CA, Hommer DW, Momenan R (2013) Deficits in cortical, diencephalic and midbrain gray matter in alcoholism measured by VBM: Effects of co-morbid substance abuse. Neuroimage Clin 2: 469-476.

39. Nakamura-Palacios EM, de Almeida Benevides MC, da Penha Zago-Gomes M, de Oliveira RW, de Vasconcellos VF, et al. (2012) Auditory event-related potentials (P3) and cognitive changes induced by frontal direct current stimulation in alcoholics according to Lesch alcoholism typology. Int $J$ Neuropsychopharmacol 15: 601-616.

40. Ridley NJ, Draper B, Withall A (2013) Alcohol-related dementia: an update of the evidence. Alzheimers Res Ther 5: 3.

41. Sullivan EV, Harding AJ, Pentney R, Dlugos C, Martin PR, et al. (2003) Disruption of frontocerebellar circuitry and function in alcoholism. Alcohol Clin Exp Res 27: 301-309.

42. Bergmann JN, Stockman JK (2015) How does intimate partner violence affect condom and oral contraceptive use in the United States? A systematic review of the literature. Contraception 91: 438-455.

43. Protogerou C, Flisher AJ, Wild LG (2014) Factors shaping condom use among South African university students: a thematic analysis. J Psychol Afr 24: 215-224.

44. Black A, Hodgetts D, King P (2020) Women's everyday resistance to intimate partner violence. Fem Psychol 30: 529-549.

45. Tolmie J, Smith, R, Short J, Wilson D, Sach J (2018) Social entrapment: A realistic understanding of the criminal offending of primary victims of intimate partner violence. New Zealand Law Review 2: 181-217.

46. Park J, Nordstrom SK, Weber KM, Irwin T (2016) Reproductive coercion uncloaking an imbalance of social power. Am J Obstet Gynecol 214: 74-78.

47. Grace KT, Perrin NA, Clough A, Miller E, Glass NE (2020) Correlates of reproductive coercion among college women in abusive relationships: baseline data from the college safety study. J Am Coll Health 16: 1-8.

48. Cooper ML (2002) Alcohol use and risky sexual behavior among college students and youth: evaluating the evidence. J Stud Alcohol Suppl : 101-117.

49. Davis KC, Masters NT, Eakins D, Danube CL, George WH, et al. (2014) Alcohol intoxication and condom use self-efficacy effects on women's condom use intentions. Addict Behav 39: 153-158.

50. Gilmore AK, Granato HF, Lewis MA (2013) The use of drinking and condomrelated protective strategies in association with condom use and sex-related alcohol use. J Sex Res 50: 470-479.

51. Livingston JA, Testa M, Windle M, Bay-Cheng LY (2015) Sexual risk at first coitus: Does alcohol make a difference? J Adolesc 43: 148-158.

52. Parks KA, Collins RL, Derrick JL (2012) The influence of marijuana and alcohol use on condom use behavior: findings from a sample of young adult female bar drinkers. Psychol Addict Behav 26: 888-894.

53. Senf JH, Price CQ (1994) Young adults, alcohol and condom use: what is the connection? J Adolesc Health 15: 238-244.
54. Weir BW, Latkin CA (2015) Alcohol, intercourse, and condom use among women recently involved in the criminal justice system: Findings from integrated global-frequency and event-level methods. AIDS Behav 19: 10481060.

55. Okoro UJ, Carey KB, Johnson BT, Carey MP, Scott-Sheldon LAJ (2019) Alcohol consumption, risky sexual behaviors, and HIV in Nigeria: A metaanalytic review. Curr Drug Res Rev 11: 92-110.

56. Chen Y, Li X, Zhang C, Hong Y, Zhou Y (2013) Alcohol use and sexual risks: use of the Alcohol Use Disorders Identification Test (AUDIT) among female sex workers in China. Health Care Women Int 34: 122-138.

57. Faye A, Faye MD, Leye MM, Diongue M, Niang K, et al. (2014) Study of determinants of unprotected sex in sailors of the Senegalese merchant navy. Bull Soc Pathol Exot 107: 115-120.

58. Fentahun N, Mamo A (2014) Risky sexual behaviors and associated factors among male and female students in Jimma Zone preparatory schools, South West Ethiopia: comparative study. Ethiop J Health Sci 24: 59-68.

59. Gallo MF, Warner L, Bell AJ, Bukusi EA, Sharma A, et al. (2011) Determinants of condom use among female sex workers in Kenya: a case-crossover analysis. J Womens Health (Larchmt) 20: 733-738.

60. Matovu JK, Ssebadduka NB (2013) Knowledge, attitudes \& barriers to condom use among female sex workers and truck drivers in Uganda: a mixed-methods study. Afr Health Sci 13: 1027-1033.

61. Mola R, Pitangui AC, Barbosa SA, Almeida LS, Sousa MR, et al. (2016) Condom use and alcohol consumption in adolescents and youth. Einstein (Sao Paulo) 14: 143-151.

62. Xiao Z, Palmgreen P, Zimmerman R, Noar S (2010) Adapting and applying a multiple domain model of condom use to Chinese college students. AIDS Care 22: 332-338.

63. Jargin SV (2019) International conflicts and overpopulation. Current Politics and Economics of Northern and Western Asia 28.

64. Grace KT, Fleming C (2016) A Systematic Review of Reproductive Coercion in International Settings. World Med Health Policy 8: 382-408.

65. Adams CE, Wald M (2009) Risks and complications of vasectomy. Urol Clin North Am 36: 331-336.

66. Rayala BZ, Viera AJ (2013) Common questions about vasectomy. Am Fam Physician 88: 757-761.

67. Likhachev VK (2014) Operative obstetrics with a phantom course. MIA, Moscow (in Russian).

68. Chernukha EA (2002) Is cesarean section at a pregnant woman's will justified? Akush Ginekol (Mosk) (in Russian) 6: 3-7.

69. Jargin SV (2018) Cesarean combined with tubal sterilization: some medical and demographic aspects. Revista Brasileira de Saúde Materno Infantil 18: 677-679. 